\title{
Review on Application of Plant Tissue Culture in Plant Breeding
}

\author{
Abenezer Abebe Tefera \\ Jimma University, Department of Plant Science and Horticulture
}

\begin{abstract}
Plant breeders employ a variety of techniques to improve the genetic composition of crops and a successful strategy is dependent on the physical, physiological and hereditary characteristics of the plant. Plant tissue culture is one of the method used in plant breeding used in disease free plant development, genetic transformation, Somatic embryogenesis, embryo rescue, and anther and ovule culture for post fertilizer barrier and polyploidy induction. It play great role in plant/crop improvement as it involves in variation creation, conservation of germplasm and shorten the breeding cycle by developing homozygous parents with single a generation. So, the review is designed to assess application of tissue culture in improvement of field crop, ornamental, forest tree or plants as whole for human benefits.
\end{abstract}

Keywords: plant, tissue culture, breeding

DOI: $10.7176 / J N S R / 9-3-03$

\section{Introduction}

Plant tissue culture broadly refers to growing plant cells, tissues, organs, seeds, or other plant parts in a sterile environment on a nutrient medium. Research in plant tissue culture over the past several decades has led to the development of techniques now used commercially across the globe to rapidly multiply a wide range of crops and improve their production systems (Zulkarnain et al., 2015).The theoretical bases of plant tissue culture was first proposed by Gottleib Haberlandt in 1902 after his experiment on culture of single cell from photosynthetic leaf cell, but, the concept evolves into a powerful tool utilized throughout the plant sciences since 105 years after his work even he were not realized the idea very well (Touchell et al., 2008). Pennazio (2001) and Kieber (2002) suggested that the discovery of auxin by Frits Warmolt Went in 1926 and cytokine by Folke Skoog and colleagues in the 1950s, led to the first success of in vitro techniques in plant tissues culture. A relative high level of auxin to cytokines favored rooting, the reverse led to shoot formation and intermediate levels to the proliferation of callus or wound parenchyma tissue (Thorpe, 2006). In addition to the formation of unipolar shoot buds and roots, the formations of bipolar somatic embryos (carrot) were first reported independently by Reinert $(1958,1959)$ and Steward et al. (1958). Beside, different scientist has been cultured ovary and anther using growth medium at aseptic condition and obtained satisfactory result that able to serve as base for today's technology. With the increasing volume of relevant publications, geneticists and plant breeders are evincing increased interest in the potential practical applications of tissue and cell culture to plant breeding.

Plant breeding is the use of natural and artificial selection to produce heritable variations and novel combinations of alleles in plants and to identify plants with novel and useful properties. Plant breeders employ a variety of techniques to improve the genetic composition of the crop and a successful strategy is dependent on the physical, physiological and hereditary characteristics of the plant. The methods used by plant breeders have developed along with the advancement of human civilization and have expanded to incorporate humanity's increased knowledge of genetics

Plant tissue culture is one of the method used in plant breeding used in disease free plant development, genetic transformation, Somatic embryogenesis (initiation embryo from somatic cell), embryo rescue, and anther and ovule culture for post fertilizer barrier and polyploidy induction(Touchell et al., 2008). Tissue culture has been exploited to create genetic variability from which crop plants can be improved, to improve the state of health of the planted material and to increase the number of desirable germplasmes available to the plant breeder. Moreover, in vitro techniques for the culture of protoplasts, anthers, microspores, ovules and embryos have been used to create new genetic variation in the breeding lines, often via haploid production (Brown and Thorpe, 1995). Crop improvement efforts through the glorification of the conventional methods, to obtain pure strains can take six to seven generations of self-pollination or crosses. Through tissue culture techniques, can be obtained homozygote plants in a short time by producing haploid plants through pollen culture, anther or ovaries followed by chromosome doubling. Having this idea the objective of the review could be stated as follow;

\section{Objective}

* To review the application of plant tissue culture in breeding of different plant or crops

\section{Literature Review}

Plant breeding and crop production, both by traditional and biotechnological methods, increasingly rely on plant tissue culture (in-vitro culture) as a mainstream tool that provides key opportunities for plant quality enhancement 
and subsequent economic sustainability. By propagation in vitro, new and/or elite plants can be mass-propagated with far greater speed than through traditional methods. The application of plant tissue culture in plant breeding has been identified by various scientists and these work reviewed one by one here below.

\section{In Vitro pollination and embryo rescue}

The formation of viable seeds in vitro after the application of pollen to the ovule surface of excised placentae was first reported in the early 1960s for poppy papaver somniferum (Kanta et al., 1962). The process has been done via excised ovules and pollen grains and grown together in the same medium and used to produce interspecific and intergeneric hybrids. As indicated by the researcher direct in vitro pollination of ovules may be useful in overcoming some stigma/style incompatibility barriers (pre-fertilization barrier).

Popielarska (2005) studied in vitro self-pollination of isolated sunflower ovules by culturing the ovule and pollen on modified MS culture media. Then reported that his work was successful in obtaining important seedling in the culture and pointed that his work will serve as base for future. Modification of the medium and semi in vivo techniques could improve pollen germination and tube growth in sunflower obtaining seedlings after in vitro pollination of isolated sunflower ovules.

Embryo culture, sometimes called embryo rescue, is an in vitro technique that has been used to save the hybrid products of fertilization when they might otherwise degenerate. It also had its beginning early in the nineteenth century, when Hannig in 1904 successfully cultured cruciferous embryos and Brown in 1906 barley embryos (Monnier, 1995).

Fathi and Jahani (2012) reviewed embryo culture in fruit tree and the basic premise for this technique is that the integrity of the hybrid genome is retained in a developmentally arrested or an abortive embryo and that its potential to resume normal growth may be realized if supplied with the proper growth substances. They were also pointed that mature embryos culturing from ripened seeds is used to eliminate seed germination inhibitors or to shorten the breeding cycle. Finally, they conclude that the method used to rescue embryos from interspecific and intergeneric crosses and from embryos that do not fully develop naturally and also to rescue seedless triploid embryos, produce haploids, overcome seed dormancy or determine seed viability.

Szała et al. (2016) conducted an experiment on Application of in vitro pollination of opened ovaries to obtain Brassica oleracea $L . \times B$. rapa $L$. hybrids. Resynthesizes of $B$. napus has been performed through interspecific hybridization of $B$. oleracea $\times B$. rapa followed by embryo rescue and genome doubling. Naturally, pollination is not good enough due to certain stigma/style barriers and so, $B$. rapa pollen was placed in vitro on an opened $B$. oleracea ovary (with style removed). Following the study, they reported that successfully B. napus has been developed and broaden its genetic make for different traits.

\section{Soma clonal-Variation}

The term 'soma-clone' was coined to refer to plants derived from any form of cell culture, and the term 'somaclonal variation' was coined to refer to the genetic variation among such plants and studies on it are important for its control and possible suppression with the aim of producing genetically identical plants, and for its use as tools to produce genetic variability, which will enable breeders the genetic improvement and (leva et al., 2012).

Soma-clonal variations are thought to be derived from "newly induced mutations" arising from the tissue culture process as well as from "pre-existing mutations" in explants (Sato et al., 2012). In vitro, the conditions of culture can be mutagenic and regenerated plants derived from organ cultures, calli, protoplasts and somatic embryos sometimes can show phenotypic and genotypic variation(Orbović et al., 2008). Soma-clonal variation provides a valuable source of genetic variation for the improvement of crops through the selection of novel variants, which may show resistance to disease, improved quality, or higher yield(Emaldi et al., 2004).

The soma-clonal variation generated by somatic embryogenesis presents a novel opportunity for olive breeders to experiment with new traits, in contrast to conventional long-term strategies for developing olive trees that have desirable new traits. Somatic embryogenesis using explants isolated from selected adult trees has allowed the regeneration of several olive cultivars. Mencuccini (2011) reported that soma clonal variation among olive plants produced by somatic embryogenesis from callus of the cultivar Moraiolo that coincide with preliminary data recorded for field-grown juvenile olive plants. A practical example of this potential is a dwarf olive tree identified among the Bush olive soma -clone (BOS) plants; the aesthetic, ecological and growth-habit characteristics of this individual support its use as an ornamental plant (leva et al., 2012).

\section{Haploid and Doubled haploids Production}

Breeders have used different methods to fix and develop homozygous genotypes through isolation of homozygous and homogeneous genotypes through conventional inbreeding methods which take several cycle inbreeding and selection and this also may not produce true homozygous line. However, now a day, plant tissue culture advanced and haploid and double haploid production through anther and ovule culture have been practicing (Tadesse et al., 2013). 
Haploids are plants with a gametophyte chromosome number and doubled haploids are haploids that have undergone chromosome duplication. There are several available methods to obtain haploids and DHs, of which in vitro anther or isolated microspore culture are the most effective and widely used (Germanà., 2011). Haploid production has been conducted for crops like bread wheat, tobacco and rice through anther. Accordingly, antherculture exploits the fact that a certain proportion of pollen grains in situ are embryogenic and these pollen grains can develop into embryos only when they are placed on artificial medium (Tadesse et al., 2013).

Doubled haploids, which are developed either spontaneously or by colchicines-induced chromosomal doubling, leads to direct production of completely homozygous lines from heterozygous plants in a single generation. Doubled haploid breeding through anther culture has emerged as an exciting and powerful tool, and a convenient alternative to conventional techniques for crop improvement (Purwoko et al., 2010). Moreover, doubled haploid technique saves at least three to four generations of self-pollination for the fixation of homozygous pure lines (Hassawi et al., 2005). Barkley and Chumley (2011) demonstrated the advantages of a DH laboratory for a Kansas wheat breeding program using economic model analysis that the rate of change in yield potential is $150 \%$ greater with the use of $\mathrm{DH}$, relative to the baseline scenario of a conventional breeding program.

Wang et al. (2014) conducted characterization of in vitro haploid and doubled haploid Chrysanthemum morifolium plants via unfertilized ovule culture for phenotypical traits and reported that both the haploid and the doubled haploids produced yellow flowers, whereas those of the maternal parental cultivar were mauve/purple. This technique employed due to highly heterozygous state of the plant that complicates molecular analysis. Intensive breeding has produced a large array of flower color and form, nevertheless, market pressure for further innovation has driven the industry to continue to seek novelty, along with a continuous need to improve levels of biotic and abiotic stress resistance (Chandler and Sanchez, 2012).

Mishra and Rao (2016) reviewed application of double haploid techniques in the improvement of rice using anther culture/in vitro androgenesis. They were reported that to some extent isolation of doubled haploid indica hybrid lines through in vitro anther culture with high yielding and superior grain quality has been successful, numerous endogenous and exogenous factors able to affect the success. Suggest that selection of better responsive rice genotypes and manipulation of the non-genetic factors like culture medium components and pre- and postculture conditions can enhance the anther culture ability in rice.

Double haploid rice lines are more viable and more than 100 rice breeding lines or varieties have been developed through anther culture in China and several anther derived lines have been reported in India, Japan, South Korea, Hungary and USA (Siddique, 2015).

\section{Somatic hybridization}

Somatic hybridization (SH) via protoplast fusion is an important tool for the production of interspecific and intergeneric hybrids and involves the fusing protoplasts of two different genomes followed by the selection of desired somatic hybrid cells and subsequent regeneration of hybrid plant. It is efficient mean of gene transfer from one species to another so as to break the crossing barriers and integration of parental nuclear and cytoplasmic genomes. SH has been widely exploited in different horticultural crops to create novel hybrids with increased yield and resistance to diseases. In addition, it has also been used for salt tolerance, quality improvement, transfer of cytoplasmic male sterility (CMS), seedless triploids and rootstock improvement (Wang et al., 2013).

Somatic hybridization by protoplast fusion has overcome many problems related to Citrus reproductive characteristics, allowing the creation of novel genotypes.SH in Citrus resulted in rootstock's resistance to various biotic and abiotic stresses and increased yield as well as fruit quality (Soriano et al., 2012). Fused protoplasts of "Bonanza" navel orange (C. sinensis) with "Red Blush" grapefruit (C. paradisi) regenerated plants that flowered precociously (Guo et al., 2000).

As plant cells have an inhibiting cell wall it is very difficult to fuse them. But isolated protoplasts were observed to fuse spontaneously because now the only barrier between the cytoplasm of two cells is the plasma membrane. After lot of refinements the techniques for protoplast fusion became important to produce hybrids from sexually incompatible species. Somatic hybridization should involve the following process: protoplast isolation, protoplast fusion, selection of somatic hybrids, and culture of somatic hybrids to regenerate complete plants. Plant cells from which the cell wall has been enzymatically or mechanically removed are called protoplasts. Regeneration of new species and improved culture techniques opened new horizons for practical breeding in a number of crops (Eeckhaut et al., 2013). Multiple resistances were also found, along with high morphological and agronomic variation (Thieme et al., 2010). Jiang et al. (2009) obtained Brassica napus + Camelina sativa hybrids with increased linolenic acid content compared to the B. napus partner. Intergeneric hybridization has been attempted in cereals, with somatic hybrids being generated between rice (O. sativa) and barley, Hordeum vulgare (Kisaka et al., 1998) rice with Zizania latifolia (Liu et al., 1999).

\section{Genetic transformation}

Genetic transformation is the most recent aspect of plant cell and tissue culture that provides the means of transfer 
of genes with desirable trait into host plants and recovery of transgenic plants. The technique has a great potential of genetic improvement of various crop plants by integrating in plant biotechnology and breeding programmes. It has a promising role for the introduction of agronomic important traits such as increased yield, better quality and enhanced resistance to pests and diseases (Sinclair et al., 2004). Genetic transformation in plants can be achieved by either vector-mediated (indirect gene transfer) or vectorless (direct gene transfer) method. Among vector dependant gene transfer methods, Agrobacterium-mediated genetic transformation is most widely used for the expression of foreign genes in plant cells.

Recently successful transgenic plants of Jatropha were obtained by direct DNA delivery to mature seedderived shoot apices via particle bombardment method (Purkayastha et al., 2010). This technology has an important impact on the reduction of toxic substances in seeds to overcoming the obstacle of seed utilization in various industrial sectors. Regeneration of disease or viral resistant plants is now achieved by employing genetic transformation technique.

Sidorov (2013) reviewed the approaches genetic transformation of crops soybean, cotton and corn. In the paper reported that Roundup Ready ${ }^{\circledR}$ soybean variety developed by Monsanto was one of the first transgenic crop for herbicide resistant commercialized in 1996. It is developed from bacterial gene of glyphosate-tolerant variant of EPSP syntheses (CP4) transformation, by particle bombardment, into embryonic axes of excised soybean embryos, which were regenerated into plants by organogenesis. Beside, insect resistant cotton, Bollgard ${ }^{\circledR} \operatorname{cotton}$, which was first transformed in 1987 was commercially released in 1996.

\section{Genetic resource conservation}

Conservation of plant genetic resources is necessary for food security and agro-biodiversity which need better use of a broader range of genetic diversity across the globe. Genetic diversity provides options to develop through selection and breeding of new and more productive crops, resistant to biological and environmental stresses (Rao, 2004). Advances in cut age technology, especially in the area of in vitro culture techniques and molecular biology provide some important tools for improved conservation and management of plant genetic resources. In vitro culture is a feasible alternative for genetic conservation of plants where the seed banking is not possible. It will be conducted either by slow growth procedures (plantlets on media) or cryopreservation (long term storage in liquid nitrogen). DNA banks provide novel options for gene banks (Ganeshan, 2006).

Slow growth methods allow plant material to be held for a few years under tissue culture conditions with periodic sub-culturing which include growing under sterile conditions and constant environmental factors of plant germplasm on artificial culture media. It is more useful where the seed banking is not possible, such as vegetative propagated plants, recalcitrant seed species, and plants with unavailable or non-viable seeds due to damage of grazing or diseases, and large and fleshy seeds (e.g Saccharum, Solanum spp., Musa spp and etc). Explants are mostly shoot, leaf, flower pieces, immature embryos, hypocotyls fragments or cotyledons (Paunesca, 2009).

Kaviani (2011) reviewed cryopreservation is one of the method in vitro culture/tissue culture used preserve plant material and involves storage of plant material (such as seed, shoot tip, zygotic and somatic embryos and pollen) at ultra-low temperatures in $\mathrm{LN}\left(-196^{\circ} \mathrm{C}\right)$ or its vapor phase $\left(-150^{\circ} \mathrm{C}\right)$. The method was developed to avoid the genetic alterations that may occur in long tissue cultures storage. At this temperature, cell division, metabolic, and biochemical activities remain suspended and the material can be stored without changes and deterioration for long time (Walters et al., 2009). The breeding process is a continuous that needs sustainable access of raw material/plant material and the conserved one can fill this gap.

\section{Pathogen Eradication}

Crop plants, especially vegetatively propagated varieties are generally infected with pathogens. The most significant advantages offered by micro propagation are large numbers of disease free propagules can be obtained from a single plant in a short period, propagation can be carried out throughout the year and the propagating material can be accommodated in a small space, reduction of labor costs for germplasm maintenance, avoidance of field inspections and environmental hazards, easy availability of material for micro propagation and rapid multiplication (Mtui, 2011).

Habtamu and Mohammed (2016) assessed the role of tissue culture in production of disease free plant material for major horticultural crops in Ethiopia. Accordingly, research centers like Jimma, Melkasa, Holeta and Debre Zeit agricultural research centers working in on high yielding and coffee berry disease resisted hybrids of coffee as well as pineapple, banana, potato and tef, respectively. Jimma Agricultural Research Center were delivered the first 2000 pineapple plantlets to Teso pineapple cooperatives in SNNPR and another 5,500 plantlets are ready for dispatch to each of the Dara and Chuko Woreda farmer. At Holeta agricultural research center over 20,000 in vitro disease free potato plants were produced since of Gudene, Jalene, Belete and Awash for 2011/12 cropping. This method is used as a control approach to viral and bacterial diseases which are commonly spread through propagative materials (Abraham, 2009). 


\section{Conclusion}

Plant tissue culture represents the most promising areas of application at present time and giving an out look into the future. The areas ranges from micro-propagation of ornamental and forest trees, production of pharmaceutically interesting compounds, and plant breeding for improved nutritional value of staple crop plants, and conservation of plant genetic resources. All biotechnological approaches like genetic transformation, haploid and double haploid induction, or soma-clonal variation to improve traits strongly depends on an efficient in-vitro plant regeneration system. Though soma-clonal variations during tissue culture are important to develop new cultivar with novel traits, for ensuring quality of our crop products it is better to eliminate soma-clonal variants depending on our interest.

There are many useful plant-derived substances which can be produced in tissue cultures. The ability to accelerate the conventional multiplication rate can be of great benefit to many countries where a disease or some climatic disaster wipes out crops. The loss of genetic resources is a common story when germplasm is held in field gene banks. Slow growth in vitro storage and cryopreservation are being proposed as solutions to the problems inherent in field gene banks. They are the means by which future generations will be able to have access to genetic resources for simple conventional breeding programmes, or for the more complex genetic transformation work.

Generally, plant tissue culture play great role in plant/crop improvement as it involves in variation creation, conservation of germplasm and shorten the breeding cycle by developing homozygous parents with single generation.

\section{Reference}

Barkley, A., and Chumley, F.G.., 2011. A doubled haploid laboratory for Kansas wheat breeding: an economic analysis of biotechnology adoption. Int Food Agribus Manag Rev, 15, pp.99-120.

Brown, D.C.W. and Thorpe, T.A., 1995. Crop improvement through tissue culture.World Journal of Microbiology and Biotechnology, 11(4), pp.409-415.

Chandler, S.F. and Sanchez, C., 2012. Genetic modification; the development of transgenic ornamental plant varieties.Plant biotechnology journal, 10(8), pp.891-903.

Eeckhaut, T., Lakshmanan, P.S., Deryckere, D., Van Bockstaele, E. and Van Huylenbroeck, J., 2013.Progress in plant protoplast research. Planta, 238(6), pp.991-1003.

Emaldi, U., Trujillo, I. and de García, E., 2004. Comparison of characteristics of bananas (Musa sp.) from the somaclone CIEN BTA-03 and its parental clone Williams. Fruits, 59(4), pp.257-263.

Fathi, H. and Jahani, U., 2012. Review of embryo culture in fruit trees. Ann Biol Res, 3(9), pp.4276-4281.

Germanà, M.A., 2011. Anther culture for haploid and doubled haploid production. Plant Cell, Tissue and Organ Culture (PCTOC), 104(3), pp.283-300.

Guo, W.W., Deng, X.X. and Yi, H.L., 2000. Somatic hybrids between navel orange (Citrus sinensis) and grapefruit (C. paradisi) for seedless triploid breeding.Euphytica, 116(3), pp.281-285.

Hassawi, D.S., Qrunfleh, I. and Dradkah, N., 2005. Production of doubled haploids from some Jordanian wheat cultivars via anther culture technique.Journal of Food Agriculture and Environment, 3(1), pp.161-164.

Jiang, J.J., Zhao, X.X., Tian, W., Li, T.B. and Wang, Y.P., 2009. Intertribal somatic hybrids between Brassica napus and Camelina sativa with high linolenic acid content. Plant Cell, Tissue and Organ Culture (PCTOC), 99(1), pp.91-95.

Kanta, K., Swamy, N.R. and Maheshwari, P., 1962. Test-tube fertilization in a flowering plant.Nature, 194(4835), pp.1214-1217.

Kaviani, B., 2011. Conservation of plant genetic resources by cryopreservation.Aust J Crop Sci, 5(6), pp.778-800.

Kieber, J.J., 2002. Tribute to Folke Skoog: recent advances in our understanding of cytokinin biology. Journal of plant growth regulation, 21(1), pp.1-2.

Kisaka, H., Kisaka, M., Kanno, A. and Kameya, T., 1998.Intergeneric somatic hybridization of rice (Oryza sativa L.) and barley (Hordeum vulgare L.) by protoplast fusion. Plant cell reports, 17(5), pp.362-367.

Leva, A.R., Rinaldi, L.M.R. and Petruccelli, R., 2012. Somaclonal variation in tissue culture: a case study with olive. INTECH Open Access Publisher.

Liu, J. and Deng, X., 1999. Production of hybrid calluses via donor-recipient fusion between Microcitrus papuana and Citrus sinensis. Plant cell, tissue and organ culture, 59(2), pp.81-87.

Mencuccini, M., 2011.Produzione di somacloni da cultivar di olivo e prime osservazioni in campo.I Convegno Nazionale dell'Olivo e dell'Olio, 1, pp.113-116.

Monnier, M., 1995.Culture of zygotic embryos.In In vitro embryogenesis in plants (pp. 117-153).Springer Netherlands.

Orbović, V., Ćalović, M., Viloria, Z., Nielsen, B., Gmitter, F.G., Castle, W.S. and Grosser, J.W., 2008.Analysis of genetic variability in various tissue culture-derived lemon plant populations using RAPD and flow cytometry.Euphytica, 161(3), pp.329-335.

Paunescu, A., 2009. Biotechnology for endangered plant conservation: a critical overview. Romanian Biotechnological Letters, 14(1), pp.4095-4103. 
Pennazio, S., 2001.The discovery of the chemical nature of the plant hormone auxin.Rivista di biologia, 95(2), pp.289-308.

Popielarska, M., 2005.In vitro pollination of isolated ovules of sunflower (Helianthus annuus L.).Acta Biologica Cracoviensia, 47(1), pp.85-92.

Purkayastha, J., Sugla, T., Paul, A., Solleti, S.K., Mazumdar, P., Basu, A., Mohommad, A., Ahmed, Z. and Sahoo, L., 2010.Efficient in vitro plant regeneration from shoot apices and gene transfer by particle bombardment in Jatropha curcas.Biologia Plantarum, 54(1), pp.13-20.

Rao, N.K., 2004. Plant genetic resources: advancing conservation and use through biotechnology. African Journal of biotechnology, 3(2), pp.136-145.

Reinert, J., 1958. Morphogenese und ihre Kontrolle an Gewebekulturen aus Carotten. Naturwissenschaften, 45(14), pp.344-345..

Reinert, J., 1959. Über die Kontrolle der Morphogenese und die Induktion von Adventivembryonen an Gewebekulturen aus Karotten. Planta, 53(4), pp.318-333.

Sato, M., Hosokawa, M. and Doi, M., 2011. Somaclonal variation is induced de novo via the tissue culture process: a study quantifying mutated cells in Saintpaulia. PLoS One, 6(8), p.e23541.

Sinclair, T.R., Purcell, L.C. and Sneller, C.H., 2004. Crop transformation and the challenge to increase yield potential.Trends in plant science, $9(2)$, pp.70-75

Soriano, L., Mourão Filho, F.D.A.A., Camargo, L.E.A., Cristofani-Yaly, M., Latado, R.R., de Andrade Pacheco, C., de Azevedo, F.A. and Mendes, B.M.J., 2012.Regeneration and characterization of somatic hybrids combining sweet orange and mandarin/mandarin hybrid cultivars for citrus scion improvement. Plant Cell, Tissue and Organ Culture (PCTOC), 111(3), pp.385-392.

Steward, F.C., Mapes, M.O. and Mears, K., 1958.Growth and organized development of cultured cells. II. Organization in cultures grown from freely suspended cells. American J Patade, V.Y. and Suprasanna, P., 2008. Radiation induced in vitro mutagenesis for sugarcane improvement. Sugar Tech, 10(1), pp.14-19.ournal of Botany, pp.705-708.

Tadesse, W., Tawkaz, S., Inagaki, M.N., Picard, E. and Baum, M., 2013.Methods and Applications of Doubled Haploid Technology in Wheat Breeding.ICARDA, Aleppo, Syria, p.36.

Thieme, R., Rakosy-Tican, E., Nachtigall, M., Schubert, J., Hammann, T., Antonova, O., Gavrilenko, T., Heimbach, U. and Thieme, T., 2010.Characterization of the multiple resistance traits of somatic hybrids between Solanum cardiophyllum Lindl.and two commercial potato cultivars. Plant cell reports, 29(10), pp.1187-1201.

Thorpe, T.A., 2006. History of plant tissue culture. Plant cell culture protocols, pp.9-32.

Touchell, D., Smith, J. and Ranney, T.G., 2008. Novel applications of plant tissue culture.In Combined Proceedings International Plant Propagators' Society (Vol. 58, p. 22).

Wang, H., Dong, B., Jiang, J., Fang, W., Guan, Z., Liao, Y., Chen, S. and Chen, F., 2014. Characterization of in vitro haploid and doubled haploid Chrysanthemum morifolium plants via unfertilized ovule culture for phenotypical traits and DNA methylation pattern. Frontiers in plant science, 5, p.738.

Wang, J., Jiang, J. and Wang, Y., 2013. Protoplast fusion for crop improvement and breeding in China. Plant Cell, Tissue and Organ Culture (PCTOC), 112(2), pp.131-142.

Zulkarnain, Z., Tapingkae, T. and Taji, A., 2015.Applications of In Vitro Techniques in Plant Breeding. In Advances in Plant Breeding Strategies: Breeding, Biotechnology and Molecular Tools (pp. 293-328). Springer International Publishing.

Sidorov, V.A., 2013. Plant tissue culture in biotechnology: recent advances in transformation through somatic embryogenesis. Biotechnological Acta, 6(4).

Purwoko, B.S., Dewi, I.S. and Khumaida, N., 2007, June.Rice anther culture to obtain doubled-haploids with multiple tolerances.In Proceedings Asia Pacific Conference on Plant Tissue and Agribiotechnology (APaCPA) (Vol. 17, p. 21).

Mishra, R. and Rao, G.J.N., 2016. In-vitro Androgenesis in Rice: Advantages, Constraints and Future Prospects. Rice Science, 23(2), pp.57-68.

Siddique, R., 2015. Impact of different media and genotypes in improving anther culture response in rice (Oryza sativa) in Bangladesh.European Scientific Journal, 11(6).

Szała, L., Sosnowska, K., Popławska, W., Liersch, A., Olejnik, A., Kozłowska, K., Bocianowski, J. and CegielskaTaras, T., 2016. Development of new restorer lines for CMS ogura system with the use of resynthesized oilseed rape (Brassica napus L.). Breeding science, 66(4), pp.516-521.

Mtui, G., 2011. Status of biotechnology in Eastern and Central Africa.

Adane Abraham.2009. Agricultural biotechnology research and development in Ethiopia.African Journal of Biotechnology. 8 (25): 7196-7204.

Habtamu T. and Wassu M. 2016.The Role of Plant Tissue Culture to Supply Disease Free Planting Materials of Major Horticultural Crops in Ethiopia. Journal of Biology, Agriculture and Healthcare.6(1) 